\title{
FRACASSO ESCOLAR: UMA VIOLÊNCIA SIMBÓLICA NA PERSPECTIVA SOCIOLÓGICA DE BOURDIEU
}

\section{SCHOOL FAILURE: A SYMBOLIC VIOLENCE FOR THE SOCIOLOGICAL PERSPECTIVE OF BOURDIEU}

\author{
Kênia Ribeiro da Silva Hidalgo ${ }^{1}$
}

\begin{abstract}
RESUMO
Este artigo objetiva considerar o tema fracasso escolar na perspectiva sociológica abordada pelo teórico Pierre Bourdieu, influente no campo educacional. Este autor traz contribuições importantes e que muito favorecem a explicitação de tal assunto. Pretende-se, inicialmente, traçar um breve panorama histórico dos problemas relacionados à aprendizagem no universo educacional brasileiro, os quais são fruto de um sistema de ensino proposto para privilegiar a minoria. Em seguida, toma-se como referência a abordagem sociológica de Bourdieu sobre a função da escola nas sociedades capitalistas e, por fim, o conceito de Violência Simbólica no contexto escolar. Nesse contexto, intenta-se promover uma reflexão crítica acerca de práticas discursivas que disseminam valores pré-concebidos e excludentes.

Palavras-chave: Fracasso escolar. Função da escola. Violência simbólica.
\end{abstract}

\begin{abstract}
This article aims to consider the subject exclusion and school failure in the sociological perspective addressed by the influential theorist in the educational field: Pierre Bourdieu. This author brings important contributions which much favors the explanation of such matter. It is intended, first, to trace a brief historical overview of the problems related to learning in the Brazilian educational universe, which are the result of a system proposed to favor the minority. Then, taking as reference Bourdieu's sociological approach of the role of the school in capitalist societies and, finally, the concept of Symbolic Violence in schools. In this context, the promotion of a critical reflection is intended, about discursive practices that disseminate pre-designed and excludent values.

Keywords: School failure. Function of schools. Symbolic violence.
\end{abstract}

1 Doutoranda em Educação pela PUC/GO. Professora da rede pública municipal de educação de Goiânia. E-mail: keniacandy@hotmail.com 


\section{INTRODUÇÃO}

Apesar dos inúmeros estudos sobre o tema fracasso escolar e dos exaustivos esforços, ao longo da história da Educação, para encontrar explicações quanto às causas do não aprender, considera-se pertinente, ainda hoje, abordá-lo por entender que tal assunto não foi suficientemente esclarecido, uma vez que os problemas de aprendizagem persistem e se manifestam de diferentes modos no cenário educacional brasileiro.

Muito se tem discutido sobre a aprendizagem escolar. Interferências, sobretudo do ponto vista da Sociologia, têm sido importantes contribuições para a questão da aprendizagem, enquanto fatores de ordem político-econômica e sociocultural têm sido determinantes nesse assunto. O tema em questão tem sido abordado pelos educadores brasileiros de forma recorrente e exaustiva, sendo comum nos debates sobre a educação. Todavia, os problemas relativos ao não aprender ainda são muito habituais.

Ao observar as incontáveis definições apontadas por inúmeros teóricos, desde o início do século $\mathrm{XX}$, sobre o tema fracasso escolar, percebe-se um quantitativo frequente e uma diversidade de abordagens que o envolve. Contudo, a ênfase desses diferentes conceitos recai nos rótulos, sobretudo aos que as crianças são submetidas por não se adequarem ao perfil previsto pela estrutura sedimentada da escola. Para a ideologia dominante há sempre uma resposta para aqueles "mal sucedidos" no contexto escolar, e segundo essa ideologia há "os menos dotados" e "os incapacitados" ou "os não dotados" à aprendizagem. O discurso elementar corrente é de que "aqueles que são capazes vencem, aqueles que não o são, fracassam, [pois] desde sempre a escola soube ensinar" (VIAL, 1972, p. 12). Entretanto, são os chamados "portadores" de dificuldade de aprendizagem que, ironicamente, vêm desmistificando ou desmascarando o sistema posto que, tão aleivosamente, tem sido fonte de massacre e dominação de alguns poucos sobre as classes trabalhadoras, a qual permanece, ainda que inconscientemente, subjugada e manipulada pela imposição de regras - aí está à ironia - antidemocráticas, evidenciando-se assim, o distanciamento existente entre o ideal e o real.

Nidelcoff (1980) traz uma contribuição interessante a respeito desse assunto quando explica que a escola, longe de ser igualitária, acentua a desigualdade favorecendo apenas alguns poucos possuidores de uma "herança cultural" semelhante a que lhe é própria, reforçando a estrutura e estratificação de classes sociais, uma vez que são predominantes os valores burgueses de ascensão social - o esforço de cada indivíduo, cujos talentos e méritos próprios o possibilitam chegar ou não à escala de ascensão social. Este é o discurso corrente internalizado pela sociedade, o qual responsabiliza o sujeito pelo seu fracasso caso, em seu percurso estudantil, não consiga moldar-se aos padrões de aprendizagem já estabelecidos.

Objetiva-se nesse artigo tomar como referência a abordagem sociológica sob a perspectiva teórica de Bourdieu, promovendo uma reflexão interessante sobre o tema fracasso escolar visando elucidar esse problema que é contínuo e permanente no interior das salas de aula, a fim de repudiar as práticas discursivas que disseminam valores pré-elaborados e preconceituosos. Para tanto, utilizou-se da revisão bibliográfica como proposta metodológica de pesquisa para elucidação do tema proposto.

Inicialmente, traçaremos um breve panorama histórico dos problemas relacionados à aprendizagem no universo educacional brasileiro, os quais são fruto de um sistema de ensino proposto para privilegiar a minoria. A consequência é o fracasso da instituição escolar enquanto espaço de formação. Segundo Faria (2008), a universalização ao acesso, à permanência e à qualidade da educação brasileira ocorre sob condições históricas específicas e ainda hoje permanece enquanto promessa.

Em seguida, toma-se como referência a abordagem sociológica de Bourdieu sobre a função da escola nas sociedades capitalistas e, por fim, o conceito de Violência Simbólica no contexto escolar. Nesse contexto, intenta-se promover uma reflexão critica acerca de práticas discursivas que disseminam valores pré-concebidos e excludentes.

\section{Discurso educacional brasileiro sobre o fracasso escolar}

No Brasil, desde a época da República, os problemas relacionados com o rendimento escolar já existiam como apontam os documentos oficiais 
que apresentam os balanços do Sistema Nacional de Ensino, muito embora uma pequena parcela privilegiada da população - a elite - fizesse parte do ambiente escolar.

Todavia, foi em meados do século XX que os problemas não só se avolumaram, mas também se alastraram, tornando-se mais evidentes. Em defesa do ideal igualitário da sociedade moderna, tendo como tema a "oportunidade de igualdade a todos", a escola se estende às classes trabalhadoras massificando o ensino com base na ideologia nacionalista de 1930, cujo mote de "obrigatoriedade, universalidade e gratuidade do ensino" favoreceria a unidade nacional, dirimindo as diferenças existentes entre as classes sociais. De acordo com Popkewitz (1994, p. 187), a massificação da escolarização pode ser compreendida como uma "continuação do projeto de disciplinação e regulação da Reforma, mas também como uma ruptura nos sistemas de conhecimento pelos quais os indivíduos deviam se tornar membros produtivos da sociedade".

$\mathrm{Na}$ tentativa de sustentar a ideologia de igualdade de oportunidades a todos, pela via escolar, o sistema de ensino, embora tenha se ampliado para acolher o aumento veloz de sua clientela, o faz de maneira inadequada, resultando, dentre outros fatores, no alto índice de reprovação e evasão escolar, bem como no de exclusão, agravando significativamente os problemas de cunho pedagógico, de ensino e de aprendizagem.

Muitas foram as justificativas para explicar os problemas de ordem educacional, ao longo da história, no discurso pedagógico brasileiro. Inicialmente, explicações deterministas de natureza psicológica apontavam para a teoria do dom e talentos natos. Porém, com o aumento desordenado do ensino público, o foco que recaía ao educando se desloca para os métodos de ensino e para a atuação docente, passando a escola a ser objeto de estudo, ampliando a discussão sobretudo numa abordagem no âmbito social. Nessa perspectiva, ao tentar servir os determinismos sociais, a escola passa a ser considerada como inapropriada e inoperante diante da tarefa de escolarização da população.

A estreita relação entre fracasso escolar e a cultura ganha proeminência na década de 1970, com o surgimento de novas pesquisas, delineando-se a difusão da teoria da "carência cultural", que atribui ao meio sociocultural da criança pobre a causa do não aprender.

Mais recentemente, na década de 1990 e, mais expressivamente, nos anos de 2000, outro enfoque relacionado à cultura surge para justificar os problemas educativos. Intuindo reconhecer o conceito de diversidade cultural referente ao respeito às diferenças culturais compreendidas em termos "gênero", "raça" e "etnia", bem como sua relação e implicações à educação, tal enfoque ganha notoriedade no discurso educacional brasileiro.

Segundo Veiga Neto (2003), cresce a centralidade da cultura para pensar o mundo. A cultura é central, continua autora, não porque ocupe uma posição única e privilegiada, mas porque perpassa tudo o que acontece nas demais instâncias sociais como a política, a economia e a educação.

Sabe-se que a cultura foi pensada durante muito tempo como única e universal. A Modernidade defendia uma epistemologia monocultural e a Educação, em linhas gerais, era entendida como o caminho para atingir as formas mais "elevadas" da Cultura, assegurando uma escolarização que servisse a uma sociedade cada vez mais homogênea, previsível e segura.

Nos postulados contemporâneos, há uma proeminência da concepção de cultura local, versada nos hábitos, costumes, modos de pensar, sentir e agir, levando-se em conta o contexto sociocultural de cada indivíduo. Daí a importância de se considerar os conceitos de: diversidade cultural, garantindo as manifestações ético-políticas e culturais das minorias; diferença cultural, contrapondo a ideia de déficits e carência cultural; e multiculturalismo, no sentido de negar a padronização, tendo as suas diferenças reconhecidas, mas lutando contra as desigualdades sociais.

Todavia, é importante agregar aqui a proposta de Varela (1994), quando a autora pontua que se faz necessário

evitar a ilusão de que o etnocentrismo das "pedagogias tradicionais" (colocado em relevo por numerosos sociólogos da educação), seu desprezo pelas culturas não acadêmicas, sua rejeição à diversidade, possa se corrigir facilmente mediante a 
aplicação das "pedagogias renovadoras". As pedagogias renovadoras são, em geral, excessivamente psicológicas. É preciso, portanto, ir além desta dicotomia estabelecida entre tradição e renovação, para traçar novas formas de pensamento e atuação, para evitar os espontaneísmos (p. 96).

Evidentemente, os problemas educacionais ainda perduram na sociedade atual, embora inúmeros esforços tenham sido concentrados para explicar a ineficiência do papel da escola.

Dada esta ligeira abordagem histórica do panorama pedagógico brasileiro, concentrar-se-á a seguir em esboçar a organização social familiar, bem como o processo de constituição dos saberes.

\section{Escola, instituição de produção ou de reprodução social?}

A ordem social, de acordo com Bonnewitz (2003) ao referenciar Bourdieu, apresenta uma tendência em reproduzir-se. Essa reprodução cultural e reprodução social se explicam pelas várias formas "que os agentes ${ }^{2}$ mobilizam para a conservação ou para a apropriação do capital” (p. 67).

Entende-se também que no campo da educação, como nos demais campos, exista o científico, o esportivo, o político, o linguístico, enfim, estratégias de reprodução - conscientes ou não - que têm como objetivo "produzir agentes sociais capazes e dignos de receber a herança do grupo" (BOURDIEU, 1989a, p. 388, apud NOGUEIRA, 1997, p. 121).

\begin{abstract}
A definição funcionalista das funções da educação, que ignora a contribuição que o sistema de ensino traz à reprodução da estrutura social, sancionando a transmissão hereditária do capital cultural, encontra-se, de fato, implicada, desde a origem, numa definição do "capital humano" que, apesar de suas conotações "humanistas", não escapa ao economicismo e ignora, dentre outras coisas, que o rendimento escolar da ação escolar depende do capital cultural previamente investido pela família
\end{abstract}

2 Bourdieu utilizou em seus escritos a palavra "agente", literalmente, "aquele que age" (LUIGLI, 2007, p. 26). e que o rendimento econômico e social do certificado escolar depende do capital social - também herdado - que pode ser colocado a seu serviço (NOGUEIRA; CATANI, 1998, p. 74).

Nogueira e Nogueira (2003, p.40) ao citarem Bourdieu, afirmam que a escola valora não apenas o domínio de "referências culturais e linguísticas, mas também um modo específico de se relacionar com a cultura e com o saber". Desse modo, "a sociedade produz e a escola reproduz uma oposição entre dois modos diferentes que os indivíduos apresentam de se relacionar com o mundo da cultura". De um lado, aqueles que fazem parte do modo próprio dominante, cuja relação é do tipo aristocrático, familiar, íntimo da cultura "legítima", portanto, resultante de uma relação "natural" com o conhecimento escolar. Por outro lado, aqueles que fazem parte da classe social dos dominados, cuja relação com a cultura é do tipo popular, "estranha" ou distanciada do saber escolar.

A comunicação pedagógica, tal como se dá tradicionalmente na escola, exige de forma implícita, para o seu pleno aproveitamento, o domínio prévio de um conjunto de habilidades e referências culturais e linguísticas que apenas os membros das classes mais cultivadas [da cultura de elite] possuiriam. Os professores transmitem sua mensagem igualmente a todos os alunos, como se todos tivessem os mesmos instrumentos de decodificação (NOGUEIRA; NOGUEIRA, 2003, p. 38).

Nesse contexto, pode-se pensar que a educação reproduz a hierarquia social. Assim, a ideia de cultura está imbricada à ideia de classes e grupos sociais, em que se dá a luta pela manutenção da divisão de classes. As hierarquias de poder se manifestam nas relações sociais em que determinados indivíduos se submetem à vontade de outros, não ocorrendo de modo transparente, e, "vão desde o poder dos grupos e classes dominantes corporificado no Estado (...) até os inúmeros atos cotidianos nas escolas e salas de aula que são expressões sutis e complexas" (MOREIRA, 1994, p. 30).

Entretanto, se por um lado Bourdieu e Passeron (1992) acreditavam que o papel da escola é o de reprodução social, por outro, os sociólogos 
pensavam na possibilidade de a escola ser um espaço também de produção, uma vez que tem em suas bases um "padrão cultural, não apenas de repetição de comportamentos, mas de desenvolvimento (...) de raciocínios para a solução dos diferentes problemas" (BOURDIEU; PASSERON, 1992, p. 34), pois, para os autores, as estratégias existentes em um campo não se limitam à reprodução, mas se referem também à transformação.

Catani (2003, p. 18) reforça tal ideia ao afirmar que os autores acima não pretendiam "decretar a impossibilidade das transformações" no campo educacional, pois para eles, somente ao se desvelar os modos ocultos da produção da dominação e da injustiça, sob a forma de violência simbólica, é que se torna possível "a superação do indesejado" e as formas de combate por mudanças. Dito de outro modo, somente conhecendo o papel reprodutivista da escola na sociedade de classes é que se torna possível minimizar os efeitos da ação reprodutora da instituição escolar. Assim sendo, a escola pode e deve ser um espaço de produção, pois, para os autores, a escola tem um papel relevante, enquanto instituição social, no delineamento de sua existência, qual seja, a de ritualizar uma cultura própria, no sentido conferido pelo campo que a constitui e não no sentido de sua autonomia como campo isolado das relações sociais que permeiam e qualificam cultural e socialmente as suas especificidades, uma vez que possui atitudes e identidade próprias e apresenta modo próprio de agir, de criar e de transformar, constituídos mediante as várias formas em que os agentes sociais a integram, pensam, acreditam, sabem e interpretam ideologicamente.

Não se pode, portanto, absolutizar o pensamento do sociólogo francês às suas formulações teóricas sobre o sistema de ensino francês, conjunturalmente marcado pelos movimentos e inquietações políticas e intelectuais que polarizaram o mundo ocidental no final dos anos 1970. O título de sua desafiante e revolucionária obra em parceria com Passeron, $A$ Reprodução, gerou muitas interpretações em represália à destruição do mito do dom e da escola libertária de feição iluminista para todos: ela reproduz as desigualdades sociais em oposição à noção de promoção da igualdade social. Em entrevista concedida a Luke e Flores (1991, p. 3), Bourdieu afirmou:
[...] penso que a palavra reprodução, título do meu livro, teve efeito muito funesto. Impôs uma imagem simplificadora, tanto do mundo social quanto do papel do sistema escolar no mundo social. Inspirou afirmações do tipo: a teoria da reprodução diz que o sistema de educação reproduz a estrutura social tal qual ela é. Não tem cabimento reduzir-se a uma frase como esta o que eu escrevi. É verdade que La Reprodution, assim como Lês Heritiés foram escritos numa época em que, no mundo inteiro, acreditava-se e dizia-se que o sistema escolar era libertador. Na França havia a mitologia da escola libertadora, nos Estados Unidos a da mobilidade e esses meus livros foram escritos, em parte, em reação contra essas mitologias. Era preciso curvar a vara para outro lado, como dizia Mao Tse Tung, que já não é tão atacado hoje em dia... e reagir contra a mitologia da mudança permanente [...] (apud BALDINO, 2002, p. 34).

Avançando as apropriações teóricas decorrentes das variadas e significativas publicações pós $A$ Reprodução, Nogueira e Catani (1998) enfatizam que no artigo denominado Os Excluídos do Interior, de 1992, a renovação do pensamento de Bourdieu e Passeron explicita, com maior profundidade, sua compreensão quanto ao papel atribuído à escola. Afirmam que:

[...] Se, até fins da década de 50, a grande clivagem se fazia entre, de um lado, os escolarizados, e, de outro, os excluídos da escola, hoje em dia ela opera, de modo bem menos simples, através de uma segregação interna ao sistema educacional que separa os educandos segundo o itinerário escolar, o tipo de estudos, o estabelecimento de ensino, a sala de aula, as opções curriculares. Exclusão "branda", "contínua", "insensível", "despercebida". A escola segue, pois, excluindo, mas hoje ela o faz de modo mais dissimulado, conservando em seu interior os excluídos, postergando sua dissimulação, e, reservando a eles os setores escolares mais desvalorizados [...] (NOGUEIRA; CATANI, 1998, p. 13).

$\mathrm{Na}$ continuidade do processo da problematização quanto às relações entre escola-sociedade e construção dos saberes escolares, Silva (2006) pontua que a estrutura e organização da escola compreendem 
sua relação com o modelo regular democrático, isto é, adapta-se, predominando o papel de dominação e de reprodução, incorporando "os mecanismos que informam os processos pedagógicos e organizativos de gestão e de tomada de decisões" (p. 32).

Silva (2006), ao citar Viñao Frago, entende que a cultura escolar é um "conjunto de práticas, normas, ideias e procedimentos que se expressam em modos de fazer e pensar o cotidiano da escola", desse modo, todas as ações do cotidiano escolar são perpassadas pela cultura, seja sob a influência de seus ritos e linguagem, seja sob a forma determinante instituída de organização escolar (p. 32).

[percebe-se que] a escola [é] uma instituição bastante ímpar, estruturada sobre processos, normas, valores, significados, rituais e formas de pensamento que constituem sua própria cultura, à qual não é monolítica, nem estática, nem repetível (p. $33)$.

Conforme Forquin (1993), este conjunto de características do cotidiano escolar de "Cultura da Escola" contrapõe ao conceito de "Cultura Escolar", como sendo o conjunto de saberes, que uma vez organizado, compõe a base de conhecimentos sobre a qual trabalham educadores e educandos imbuídos de uma cultura humana própria, seja ela erudito-científica ou popular-senso comum, denominando-se, portanto, a instituição escolar como sendo um "mundo social", conformando-a de modo muito específico a uma prática social universal.

Já para Dominique (2001), a cultura escolar revela que a escola é um espaço de inculcar comportamentos e hábitos, não apenas repasse de conhecimentos. Para a autora, emerge-se a evidência de que a escola "não é somente um lugar de aprendizagem de saberes, mas é, ao mesmo tempo, um lugar de inculcação de comportamentos", ou seja, modos de agir, pensar e sentir de indivíduos e/ou grupos (p. 8).

Conforme Nogueira e Nogueira (2003), Bourdieu entende que não deveria haver uma cultura considerada superior à outra. Os valores que orientam um grupo social não poderiam ser arbitrários e fundados em uma perspectiva universal. Para o autor, "um arbitrário cultural corresponderia à força da classe social que o sustenta", legitimando-o na sociedade em que está inserido. Da mesma forma, a cultura transmitida na escola, não poderia ser elitista, arbitrária e universal. Todavia, a cultura da escola foi construída, ao longo da história, sob estas bases, nas quais a cultura considerada como única, da classe dominante, se legitima pela sociedade. De modo oculto, a cultura da escola se revela como neutra, isto é, não arbitrária e não relacionada a nenhuma camada social e é isso que garante sua legitimidade. De acordo com os autores, segundo a concepção sociológica de Bourdieu, "a legitimidade da instituição escolar e da ação pedagógica que nela se exerce, só pode ser garantida na medida em que o caráter arbitrário e socialmente imposto da cultura escolar é ocultado". Sendo assim, a escola passa a exercer a função de reprodução das diferenças sociais, livre de qualquer suspeita. Para isso, é necessário que a escola simplesmente "ignore (...) as desigualdades culturais entre as crianças das diferentes classes sociais". Estas representam relações bipolares entre dominantes e dominados, e apresentam modos de pensar, sentir e agir diferentes (NOGUEIRA; NOGUEIRA, 2003, p. 37-38).

\section{Violência Simbólica no contexto escolar}

Profundas transformações ocorreram ao longo dos séculos XIX e XX no que se refere à educação. Nos países europeus, nos Estados Unidos e no Brasil estabeleceram-se leis que facultavam a escolarização como obrigatória, submetendo-as ao controle do Estado, cujos conteúdos e métodos de ensino e a formação de educadores (aspectos simbólicos do sistema), foram se delineando e se definindo.

A escola foi tomada como um instrumento de construção dos cidadãos necessário ao Estado-nação, servindo à produção de indivíduos com as habilidades, sensibilidades e percepções adequadas ao funcionamento da democracia moderna em detrimento das exigências e expectativas da linhagem familiar a que estavam vinculados (ALMEIDA, 2003, p. 51).

De acordo com a citação acima, fica claro a divisão de classes e, por conseguinte, a classificação 
e hierarquização de grupos sociais, uma vez que é dada à classe dominante a posse de valores concebidos como moralizantes em detrimento dos grupos populares, materializando-se assim o modelo de cidadão moderno na sociedade. Para Almeida (2003), tal percepção, sob a defesa do Estado, serviu de base para transformá-los em valores escolares neutros, que constituiriam o cerne sobre o qual se construiria a nação moderna.

Ainda segundo Almeida, com a obrigatoriedade da escola para todos, as crianças, de origens sociais diversas, se colocam de modo diferente aos valores transmitidos pela escola, uma vez que estes são reconhecidos como universais. Nesse arranjo, a escola homogeneíza tais valores, tidos como únicos, e ignora as aprendizagens anteriores, extirpando-se assim, as "conexões sociais" da criança. Com isso, a escola oculta o processo social que tem como resultado a diferenciação dos educandos entre os que possuem "capacidades" inatas e os que não as possuem, como sendo "princípio de hierarquização das crianças", se tornando o mais "significativo determinante do destino social dos indivíduos". Sendo assim, "a exploração dos padrões morais mobilizados nas escolas (...) e o envolvimento das famílias na escola" é considerado como "princípio explicativo [do] desempenho escolar (...)". Portanto, "quando se mede o valor de uma família pelo seu envolvimento na escola dos filhos, o que está sendo medido de fato é a possibilidade que cada uma teve de construir as capacidades que permitem tal envolvimento ao longo de sua história" (ALMEIDA, 2003, p. 52-53).

A essa ideia cabe aqui apropriar-se da Teoria da Violência Simbólica, de Bourdieu, que diz respeito à formação de uma sociedade na qual se impera relações de poder entre os diferentes grupos sociais ou entre agentes de um mesmo grupo social, conferindo à classe dominante o uso de seu poder ou sua força para se beneficiar dos meios políticos, econômicos e sociais. Ao se apropriar desses benefícios, a ideia que predomina é que esses são direitos adquiridos. Desse modo, tenta-se ocultar sua patente dominação sobre a classe dominada, mediante a "imposição da disciplina", cuja legitimidade se dá pela subserviência acrítica e indiscriminada dessa classe que se conforma aos interesses determinados daquela classe, evitando-se assim o uso de sua força.
Segundo Cunha (1979), Bourdieu procura descobrir os mecanismos aos quais os grupos dominados aderem à ordem estabelecida de legitimidade e dominação dos grupos dominadores que se dá nas relações de força, sejam elas material ou simbólica, intimamente articuladas. Daí o axioma da violência simbólica, cuja ideia parte da premissa de que "todo poder de violência simbólica acrescenta sua força simbólica às relações de força material que estão na base de sua força simbólica". Dito de outra maneira, a força simbólica necessita da força material, que é a sua base, embora essa não baste para se tornar efetivamente legítima. Portanto, a violência simbólica é "a capacidade que tem os grupos detentores do poder de violência material, de impor aos grupos dominados, significações legítimas". Portanto, a formação da sociedade se dá no sistema de relações de força material e força simbólica entre grupos ou classes (CUNHA, 1979, p. 82).

Para compreender os mecanismos de Violência Simbólica é necessário entender o conceito de cultura arbitrária. Para Bourdieu, segundo os escritos de Cunha (1979, p. 84), "a arbitrariedade da cultura resulta do fato de que sua estrutura e suas funções 'não podem ser deduzidas de nenhum princípio universal"'. A cultura, ao contrário, é resultado das "condições sociais" do grupo a que pertence. Sendo assim, pode-se dizer que a arbitrariedade da cultura resulta "de condições de produção e reprodução". Bourdieu não é contra o conceito de diferentes culturas, porém estas, em sua visão, estão subordinadas a uma cultura hegemônica, já instituída e determinada, que defende os interesses das classes dominantes, às quais são colocadas em tal posição pelas relações de força.

O maior efeito dessa 'violência simbólica' exercida pela escola não é a perda da cultura familiar e a inculcação de uma nova cultura exógena (...), mas o reconhecimento, por parte dos membros [das classes menos favorecida] da superioridade e legitimidade da cultura dominante (NOGUEIRA; NOGUEIRA, 2003, p. 39).

A teoria da Violência Simbólica revela o funcionamento da estrutura do sistema educacional, cujo rótulo estampa, contraditoriamente, o slogan da escola democrática, gratuita, igualitária e para todos, 
permitindo-se compreender, nessa mesma ótica, os mecanismos que reproduzem as estruturas de classe de uma sociedade burguesa. Sahda (2002) pontua que "é a estrutura social que permite ou não que as pessoas cumpram determinados destinos [...] a escola se limita a reproduzir no seu interior a desigualdade de oportunidades que caracteriza a estrutura da nossa sociedade" (p. 15).

Para se compreender a teoria da Violência Simbólica é importante levar em consideração que "quanto maior for o capital cultural dos destinatários maior o sucesso da ação pedagógica dominante". Dito de outro modo, quanto menor a distância do capital cultural e seus destinatários, maior é o valor da ação pedagógica. Nesse contexto, a ação pedagógica familiar se torna fundante na determinação do sucesso da ação pedagógica escolar (CUNHA, 1979, p. 86).

Através da produção do habitus ${ }^{3}$ nos destinatários da ação pedagógica, o trabalho pedagógico permite produzir e reproduzir a integração moral e intelectual do grupo (...) que lhe delega a autoridade, sem recorrer à repressão externa, em particular à coação física (...). Ao mesmo tempo em que o trabalho pedagógico produz a legitimidade do produto da ação pedagógica (...), ele produz também, e indissociavelmente, a necessidade legítima desse produto e o consumidor legítimo, aquele que tem a disposição de consumi-lo nas formas legítimas (p. 93).

Cunha, referenciando Bourdieu diz que a ação pedagógica é um tipo de força simbólica que impõe a cultura dominante de um grupo sobre o outro mediante uma arbitrariedade reconhecida como legítima, pois está imbuída de autoridade e suas implicações resultam em aplicar sansões impostas, aprovadas e garantidas socialmente e, consequentemente, aceitas como autênticas. O conteúdo da ação pedagógica é selecionado pelos grupos dominantes

\footnotetext{
3 Habitus: "Conceito central da sociologia bourdieusiana. Ele garante a coerência entre a sua concepção da sociedade e a do agente social individua (...). Esse conceito está na base da reprodução da ordem social. Por isso, como princípio de conservação, ele também pode tornar-se um mecanismo de invenção e, consequentemente de mudança. (...) É um sistema de disposições duradouras adquirido pelo indivíduo durante o processo de socialização. As disposições são atitudes, inclinações para perceber, sentir, fazer e pensar, interiorizadas pelos indivíduos em razão de suas condições objetivas de existência, e que funcionam então como princípios inconscientes de ação, percepção e reflexão" (BONNEWITZ, 2003, pp. 75-77).
}

de modo arbitrário, de acordo com o que se considera como "significações dignas de serem reproduzidas". Assim, a ação pedagógica implica no que Bourdieu chama de "dupla arbitrariedade: imposição/inculcação do conteúdo e seleção/exclusão do conteúdo" às quais estão articuladas e postas dissimuladamente a fim de ocultarem suas relações de poder (CUNHA, 1979, pp. 86-87). Com isso, se constitui a ideia que a ação pedagógica ao invés de considerada arbitrária é vista como natural, necessária e inevitável. Grosso modo, a ação pedagógica precisa ser dissimulada para ocultar as relações de força material das quais partem essa arbitrariedade.

Assim como as diferentes culturas, as ações pedagógicas se organizam em um sistema, no qual uma delas ocupa posição de domínio sobre as demais, contribuindo para a reprodução da cultura dominante cujo domínio favorece a inculcação de modos de pensar, sentir e agir - o habitus - que lhes são próprios, e que, por sua vez, são incorporados ou interiorizados pelos grupos dominados e perpetuados em suas práticas ainda que a ação pedagógica tenha cessado. Contudo, a ação pedagógica dispõe das próprias instituições para instaurar e/ou promulgar sua autoridade.

Conforme Luigli (2007), Bourdieu afirma que a produção do mérito escolar revela a tendência em fortalecer as diferenças quando classifica o desempenho dos agentes ali inseridos. E isso ocorre de modo arbitrário, e "ninguém parece perceber esse mecanismo, em razão de o habitus que estrutura o seu funcionamento (...) coincidir com as condições objetivas nas quais ocorre à avaliação dos méritos dos agentes", pois, a adequação do funcionamento objetivo do sistema constituído pelo habitus é considerada natural. Portanto, o habitus, segundo Bourdieu, não ocorre de modo isolado, mas em um contexto sócio-histórico, político e econômico que determina as estruturas das trajetórias de vida de cada indivíduo e de cada grupo (LUGLI, 2007, p. 34).

Bourdieu chama a atenção para a necessidade de se identificar a posição do habitus nas relações da sociedade, suas condições concretas de existência e as possibilidades de autonomia ou dependência daí decorrentes, tanto em termos econômicos quanto sociais. É por isso que ele fala de capital social, 
capital cultural e capital escolar, em vez de utilizar somente o critério do capital econômico (...) para garantir o máximo de sucesso em cada campo (...). Ora, aqueles que serão mais bem-sucedidos serão justamente aqueles que possuírem maior capital cultural e social, que é adquirido, por definição, fora do ambiente escolar (p. 32- 34).

Um trabalho pedagógico pode apresentar duas diferentes maneiras de inculcação: a que visa modificar completamente um habitus por outro (conversão ou transformação) e a que visa manter o habitus familiar. A produtividade do trabalho pedagógico que produz seu efeito de inculcação apresenta-se em três dimensões: a) durabilidade do habitus (tempo de permanência após a cessação da ação pedagógica inculcada); b) transferibilidade do habitus (capacidade de produzir práticas de princípios culturais arbitrários em diferentes campos); c) exaustividade do habitus (capacidade de reproduzir, nas práticas que produzem os princípios da cultura arbitrária). Estas três dimensões determinam o grau de "competência legítima" do trabalho pedagógico da cultura dominante (CUNHA, 1979, 93-95). Sendo assim, a cultura hegemônica é considerada e reconhecida, tanto pelo grupo dominante quanto pelo grupo dominado de cultura legítima, universal e autêntica.

Enfim, fazendo interiorizar o habitus na subjetividade dos destinatários da ação pedagógica, o trabalho pedagógico concorre para a reprodução das estruturas objetivas das quais é produto. Dessa maneira, os grupos ou classes dominantes podem se dispensar de usar seu poder de violência material para exercer a dominação (CUNHA, 1979, p. 97).

Segundo Pereira e Andrade (2007, p. 56), a escola exclui, de maneira explícita, aqueles que não se enquadram ao padrão por ela determinado quando usa do discurso persuasivo no qual "os dons naturais justificam os rendimentos diferenciais dos alunos na escola". Desse modo, os despossuídos de capital cultural são excluídos pela aceitação passiva de tal discurso. Os educandos, bem como suas famílias, aceitam esse infortúnio com base na inculcação posta pela própria escola, que a seleção dos educandos é feita de acordo com os dons e méritos que eles possuem, estabelecendo-se assim um convencimento de que não é a escola que os rejeita por não possuírem tais dons. Assim, o "apelo aos dons naturais justifica os rendimentos diferenciais dos alunos na escola", consolidando uma estreita relação com a hierarquia social.

Após os anos 1950, mudanças no sistema de ensino ocorreram com o objetivo de acolher a classe trabalhadora em nome da "democratização". Desse modo, configura-se um paradoxo: a escola promove o acesso a todos, mas privilegia aqueles que fazem parte da cultura de elite. Assim, a escola não mais exclui de modo explícito, mas implicitamente, isto é de modo brando em que "estudantes provenientes das famílias mais desprovidas culturalmente têm todas as chances de obter, ao fim de uma longa escolaridade, muitas vezes paga com pesados sacrifícios, um diploma desvalorizado" (NOGUEIRA; CATANI, 1998, p. 221).

\begin{abstract}
(...) os sistema de ensino (...) aberto a todos [...mas] reservado a alguns, [consegue] a façanha de reunir as aparências da 'democratização' com a realidade da reprodução que se realiza em um grau superior de dissimulação, portanto, com um efeito acentuado de legitimação social (p. 223).
\end{abstract}

Nesse contexto, a escola estigmatiza sutilmente e até mesmo imperceptivelmente a exclusão da maioria e consequentemente seu fracasso, pois todos, aparentemente, são providos de oportunidades iguais. Revela-se aí, os mecanismos pelos quais a escola está imbricada "com a formação dos culturalmente privilegiados e com a reprodução das desigualdades sociais" (PEREIRA; ANDRADE, 2007, p. 59).

Assim, a escola mantém, em seu interior os excluídos, os quais optam ou por aderir à ilusão proposta por ela, resignando-se às "suas verdades", ou por se revoltarem impotentemente, ao terem que abrir mão das aspirações que a própria escola e a sociedade lhes inculcaram. Pois ao concluírem um percurso escolar recebem um certificado que não tem valor, "que não garante a adequação entre a chancela legal e o posto ocupado, ou seja, entre as aspirações proporcionadas pela certificação e os retornos materiais e simbólicos daí resultantes" (PEREIRA; ANDRADE, 2007, p. 59). 
A escola homogeneíza a todos desconsiderando suas diferenças e, de modo oculto, privilegia quem possui uma herança familiar vantajosa, à qual se designa como "a mais vantajosa" não porque ela seja mais humana e melhor, mas porque favorece a manutenção do status quo.

Nessa perspectiva, o fracasso escolar se torna a norma das classes menos favorecidas. Sainssaulieu (1972), ao citar Bourdieu e Passeron, pontua que os mecanismos mascarados pela função ideológica da escola, reproduzem as condições de manutenção da ordem social, revelando que o aceso aos benefícios do poder está ancorado ao sucesso escolar destinado aos "herdeiros" da ordem social burguesa. Ocasionandose assim, através dessa seleção obscura, o fracasso escolar da parcela maior da população, os desafortunados, os excluídos do interior, uma vez que sua origem cultural familiar está fora dos padrões elitistas, defendidos pela cultura escolar moldada pela classe dominante. Esses desfavorecidos aceitam sua condição por também considerarem seu fracasso escolar como prova de sua incapacidade. Nesse contexto, o capital cultural dos educandos proveniente de sua classe social de origem influirá no sucesso escolar, na medida em que o ethos do sistema educacional, em que está inserido, aproxima-se da cultura elitista e afasta-se da cultura das classes menos favorecidas, revelando, portanto, um contexto marcado pela exclusão em cujo sistema ecoa o privilégio da classe dominante.

\section{Considerações finais}

O termo violência é um termo amplo, derivado do latim, e tem o sentido de força. Compreende-se que violência é um comportamento que causa intencionalmente dano ou intimidação moral a outra pessoa, podendo invadir sua autonomia e integridade. Apesar das disciplinas e coações excessivas exercidas com duros castigos físicos terem sido extirpados na sociedade contemporânea, tais práticas foram substituídas pelo que Bourdieu chama de Violência Simbólica, que eficazmente, de modo sutil e silencioso, tem o mesmo efeito: o de castrar a liberdade e o direito de cada cidadão.

Considerar as contribuições de Pierre Bourdieu para o campo educacional, numa perspectiva sociológica, no que se refere aos problemas relativos à aprendizagem no espaço escolar, nos ajuda a refletir criticamente acerca da reprodução das desigualdades sociais. Essa proposição fica clara, na medida em que a escola não considera a democratização na maneira com a qual o ensino se perpetua, ignorando o habitus existente entre os agentes que constituem o ethos escolar.

Os educadores não conscientes das desigualdades desse sistema negligenciam as desigualdades sociais, econômicas e culturais de seus educandos e ao submeterem-se à ideia de que a escola é a mesma para todos, e por sua vez, o ensino deve também ser o mesmo para todos, negam a heterogeneidade do grupo ou a singularidade de cada ser, estabelecendo-se o pensamento de que os diferentes precisam se ajustar ao "padrão" reforçando-se, então, o ethos do sistema escolar, ora posto.

Em decorrência disso, de acordo com Araújo (2007) tais educadores situam-se não como autores singulares capazes de correrem o risco de ir contra uma ideia ou um conceito estabelecido como definitivo e sedimentado, mas se situam como pessoas manipuladas e/ou controladas pelo sistema. Nessa ótica, propõe-se que o ethos da autoria deva se contrapor ao ethos da reprodução. O educador-autor deve se situar fora do esperado, do previsível, do codificado, do determinado, do esquemático ou programado, da unanimidade, da permanência, desprendendo-se de si próprio em um constante movimento de deslocamentos variáveis e dinâmicos, em que novas janelas se abrem, a fim de mudarem suas práticas das quais foram, eles próprios, constituídos.

\begin{abstract}
Esse ethos leva a uma atitude de permanente reflexão e transgressão a que Foucault chamou de atitude-limite, ou seja, uma atitude não de simples negação, mas de se colocar sempre nas fronteiras para tentar ultrapassá-las, ir adiante dos limites que elas parecem impor a nós. O ethos fica bem claro quando o próprio filósofo diz que o pensamento crítico implica "uma verificação constante" (grifos do autor) (VEIGA-NETO, 2003, p.31).
\end{abstract}

A fim de se propor uma escola que cumpra com o seu papel formador, não deve se pensar em uma escola do tipo conformista, programada, repetitiva, engessada, cristalizada, fechada em si mesma, 
reprodutora da estrutura social vigente, mas deve-se ter em mente uma escola que permita ao sujeito de aprendizagem inserir-se na realidade, sendo capaz, com sua singular potência criadora, de inventar outras realidades possíveis. Nesse sentido, a escola deixa de ser um instrumento de alienação para ser um instrumento de libertação.

Romper com a estrutura excludente presente na escola e conduzir os agentes sociais nela inseridos à condição que os permita participar ativamente de seu processo de aprendizagem, fazendo da escola um espaço de crítica, de produção e significados, mediante a construção de um saber significativo e permanentemente reavaliado em face da realidade social dos educandos contribuirá para que a escola não seja mera reprodutora, formadora de sujeitos passivos, alienados, acríticos e, consequentemente, confirmadora das desigualdades.

\section{Referências}

ALMEIDA, A. M. Valores e luta simbólica. In: Bourdieu pensa a educação. Revista

educação especial: Biblioteca do Professor, n. 5, São Paulo: Segmento, 2003.

ARAÚJO, B. C. O cotidiano escolar: a linguagem articulando saberes, poderes e sujeitos. (Tese de doutorado). Goiania: UFG/GO, 2007.

BALDINO, J. M. Evasão discente na educação superior: uma questão silenciada em tempos de encantamento pela ampliação das oportunidades educacionais. (Tese de doutorado). São Paulo: UNESP/Campus Marília, 2002.

BONNEWITZ, P. Primeiras lições sobre a sociologia de $\mathbf{P}$. Bourdieu. Petrópolis: Vozes, 2003.

BOURDIEU, P; CHAMPAGNE, P. Excluídos do interior. In: NOGUEIRA, M; CATANI, A. Escritos de educação. Petrópolis: Vozes, 1998. p.217-227.

BOURDIEU, P. PASSERON, J. A reprodução: elementos para uma teoria do sistema de ensino. Petrópolis: Vozes, 1992.

CATANI, D. B. A escola como ela é. Revista brasileira de educação. maio/ago., n. 23. Campinas: Editora Autores Associados, 2003.

CUNHA, L. A. Notas para uma leitura da teoria da violência simbólica. Educação e Sociedade. CEDES, Cortez \& Moraes - set. 1979.
DOMINIQUE, J. A cultura escolar como objeto histórico. Revista brasileira de história e educação, n. 01. jan./jun. 2001.

FARIA, G. G. G. Os ciclos do fracasso escolar: concepções e proposições. (Tese de doutorado). UFG/ GO, 2008

FORQUIN, J. C. Escola e cultura: as bases sociais e epistemológicas do conhecimento escolar. Porto Alegre: Artes Médicas, 1993.

LUIGLI, R. S. G. A construção social do indivíduo. Revista Brasileira de Ciência, p. 26-35, 2007.

MOREIRA, A. F.; SILVA, T. T. (Org.). Currículo, cultura e sociedade. Cortez Editora, 1994.

NIDELCOFF, M. T. Uma escola para o povo. 5.ed. São Paulo: Editora Brasiliense, 1980.

NOGUEIRA, M. A. Convertidos e oblados: um exame da relação classes médias/escola na obra de Pierre Bourdieu. Educação, Sociedade e Culturas. Belo Horizonte, n.07, p. 109-129, 1997.

NOGUEIRA, M. A; NOGUEIRA, C. M. Um arbitrário cultural dominante. Revista brasileira de educação. maio/ ago, n. 23. Campinas: Editora Autores Associados, 2003.

PEREIRA, G. M.; ANDRADE, M. C. L. Coach Carter ou a segunda chance dos excluídos do interior. Revista Brasileira de Ciência, p.56-65, 2007.

POPKEWITZ, T. S. História do currículo, regulação social e poder. In: SILVA, T. T. (Org.). O sujeito da educação. Petrópolis: Vozes, 1994.

SAHDA, M. I. Dificuldade de Aprendizagem: uma indefinição? Revista da FAEEBA/UNEB, Depto. de Educação I , v.11, n.17, jan./jun., 2002, Salvador: UNEB, 2002, p.57-64.

SAINSSAULIEU, R. Sobre a reprodução, de Pierre Bourdieu e Jean-Glaude Passeron. 1972. In: BRANDÃO, Z. (Org.). Democratização do ensino: meta ou mito? Rio de Janeiro: F. Alves, 1987. p.139-159.

SILVA, F. C. T. Escola e cultura escolar. In: MONTEIRO; MULLER (Orgs.). Educação como espaço de cultura. Cuiabá: EDUFMT/CAPES, 2006.

VARELA, J. O estatuto do saber pedagógico. In: SILVA, T. T. (Org.). O sujeito da educação. Petrópolis: Vozes, 1994.

VEIGA-NETO, A. Cultura, culturas e educação. Revista brasileira de educação. maio/ago., n. 23. Campinas: Editora Autores Associados, 2003. 
VIAL, M. Um desafio à democratização do ensino: o fracasso escolar. In: BRANDÃO, Z. (Org.). Democratização do ensino: meta ou mito? Rio de Janeiro: F. Alves, 1987, p.11-23.
Recebido em novembro de 2013. Aceito em março de 2014. 